\title{
Effects of HPS and LED lighting on cucumber leaf photosynthesis, light quality penetration and temperature in the canopy, plant morphology and yield
}

\author{
Liisa E. Särkkä ${ }^{1}$, Kari Jokinen ${ }^{1}$, Carl-Otto Ottosen ${ }^{2}$ and Timo Kaukoranta ${ }^{1}$ \\ ${ }^{1}$ Natural Resources Institute Finland, Toivonlinnantie 518, Fl 21500 Piikkiö, Finland \\ ${ }^{2}$ Department of Food Science-Plant, Food \& Climate, Aarhus University, Kirstinebjergvej 10, \\ 5792 Årslev, Denmark \\ e-mail: liisa.sarkka@luke.fi
}

\begin{abstract}
In Nordic countries during the winter months supplemental lighting is essential for year-round cucumber production. In this research the effects of full HPS (top and interlights) illumination is compared to hybrid (HPS top, LED interlights) and full LED (top and interlights). The results showed that fruit yield was highest in the HPS-LED treatment whereas the electrical use efficiency $\left(\mathrm{kg}\right.$ yield $\mathrm{J}^{-1}$ ) increased when HPS was replaced with LED. In LED-LED the light use efficiency ( $g$ fruit FW mol-1 PAR) was highest but resulted in a fewer number of fruits in mid-winter particularly and the lowest yield potential. The lower temperature and lower light level due to LED-LED lighting lead to reduced photosynthesis capacity, flower initiation rate and water use efficiency whereas increased stem elongation and leaf expansion compared to other treatments. Differences in light quality of LED and HPS are also discussed in terms of cucumber yield formation.
\end{abstract}

Key words: greenhouse, light-emitting diode, light use efficiency, supplemental lighting

\section{Introduction}

Energy efficiency in greenhouse cultivation in Nordic countries is important for economically feasible production and to lower the industry's carbon footprint. Greenhouse cucumber is commonly cultivated at northern latitudes under high pressure sodium (HPS) supplemental lighting year-round when the solar light level (Daily light integral [DLI]) is low during fall and winter and even on cloudy summer days. Luminaire installations, both as top and intercrop lights, are frequently utilized in cucumber and tomato cultivation because of the higher yields associated with these lighting systems (Hovi et al. 2004, Hovi-Pekkanen and Tahvonen 2008). Currently, the installed lamps for both positions are of the HPS type.

LED luminaires have developed rapidly in recent years and are suitable for greenhouse use, especially for low canopy crops like lettuce and micropropagated plants (Hahn et al. 1996, Li et al. 2014). Light production efficien$c y$ is better in LED than for HPS lights ( $\mu$ mol PAR J-1 electricity) and their efficiency is increasing in contrast to HPS units (Ouzonis et al. 2015c, Pattison et al. 2016). Heat output relative to light output is higher in HPS than in LED lights and while HPS lights strongly radiate heat downward, most LED armatures lose convective heat upwards even though the light is focused on the plants. This results in lower leaf temperatures and in some cases requires more pipe borne heating, thus reducing the energy savings. The LED interlighting in contrast to the HPS luminaires can be installed very close to the plants without leaf damage resulting from excessively high temperatures from HPS lamps (Jokinen et al. 2011). Some tomato growers have recently installed LED luminaires in the middle of the canopies while HPS lamps are used as top lights and full LED installations are being introduced as well. In cucumber production, aisle width can be reduced and rows increased for enhanced cultivation if HPS interlights are replaced with LED luminaires. HPS installation as interlight has often no focusing armature, while LED interlight can be directed towards the leaves. There is, however, little information available comparing HPS supplemental lighting with LED as top and interlights, respectively, in terms of plant growth, development and energy efficiency. The colour composition of LED in interlighting may need to differ in spectrum from top lights, since blue lights alone have not been successful (Trouwborst et al. 2010).

Light and temperature are important growth factors for plants and cucumber is known to respond well to light intensity (photosynthetic photon flux (PPF) (Hovi-Pekkanen and Tahvonen 2008). However, cucumber forms a tall canopy where self-shading affects vertical spectral light distribution. The vertical distribution of temperature and light may affect plant structure and photosynthesis efficiency with consequences for yield formation. 
Several light quality studies have been done with no clear conclusions (Hogewoning et al. 2010, Trouwborst et al. 2010, Hernandez and Kubota 2014, 2015, ).

The challenge is that most of the research has been done under solely artificial lighting conditions with rather incomparable LED units (Ouzounis et al. 2015b) and even there the diodes and configuration differ dramatically between products. LED manufacturers tend to focus on a fixed spectra, typically $80 \%$ red and $20 \%$ blue, due to the high efficiency of these combinations as these are the maximum absorption spectra for chlorophyll pigments $a$ and $b$. There is evidence that also green light is used in photosynthesis (Terashima et al. 2009, Kong et al. 2015) and far red light as well (Murakami et al. 2015).

In greenhouse conditions spectral manipulation using LED might only make sense in the darkest periods of the year, or by using it outside the natural light period (Ouzounis et al. 2015a). For cucumber seedlings and different ornamental plants different blue and red ratios in LED lights have not been found to improve photosynthesis when used as supplemental light (Hernandez and Kubota 2014), but they have increased the content of phenolic acids and anthocyanins (Ouzounis et al. 2014). Ouzonis et al. 2014 reported that lighting with red LED only resulted in malformations but Hernandez and Kubota (2014) found that red LED was preferred and blue light was not beneficial. However DLI in their experiments was low, being only about $5.4 \mathrm{~mol} \mathrm{~m}^{-2} \mathrm{~d}^{-1}$. Even with low solar irradiation plants' blue light needs were satisfied (Hernandez and Kubota 2014). Even with LED light as the only light source, pepper plants benefitted from a combination of blue and red compared to red light alone (Brown et al. 1995).

Brazaityte et al. (2009) grew cucumber transplants in phytotrons and the recommended light spectrum included blue, red, far red, green and orange light. Leaves acclimate their photosystem composition to the growth light spectrum, which also suggests that a combination of different wavelengths can substantially enhance quantum yields (Hogewoning et al. 2012).

Heat radiation from luminaires and plant morphological differences caused by lamp type and light spectra induce varied transpiration rates. The heat consumed by the transpiration and applied during ventilation is a predominant part of the consumption of heat energy in a greenhouse; during warm weather humidity can be reduced by ventilation or used by a heat exchanger, both resulting in considerable energy use.

The main objectives of the study were to test feasibility of LED lighting alone or combined with HPS lighting for growing cucumber and electricity saving. Although LED as both top and interlight was an extreme lighting combination due to reduced light intensity of LED top light, we wanted to compare it to HPS if the spectral composition of LED could compensate its PPF insufficiency in cucumber high wire cultivation. Increased efficiency of electricity use was found possible (Kaukoranta et al. 2015). Based on available measurements, we aim here to clarify the physiological and physical mechanisms that led to the higher electricity use efficiency: photosynthesis response, spectrally specified light distribution, leaf and fruit temperature, growth balance, and transpiration.

\section{Materials and methods}

Greenhouse cucumber cv. Toploader was cultivated in Natural Resources Institute Finland $\left(60.39^{\circ} \mathrm{N}, 22.55^{\circ} \mathrm{E}\right)$ in three separate greenhouse compartments, $50 \mathrm{~m}^{2}$ each; each corresponding to an experimental treatment. In one compartment LED was used as both the top light and interlight (LED-LED), in the next compartment HPS was used as the top light and LED as the interlight (HPS-LED) and in the third compartment HPS was used as both the top light and interlight (HPS-HPS). HPS top lights were Philips 400 W SON-T Greenpower and HPS interlights were Philips 250 W SON-T. LED lights were Valoya AP67 with two vertical light bars in every second aisle, top lights facing down and interlights facing plant rows vertically on both sides of an aisle. The aisle width was $0.97 \mathrm{~m}$. The Valoya AP67 LED spectra was $<400 \mathrm{~nm}$ 0\%, 400-500 nm (blue) 14\%, 500-600 nm (green) 16\%, 600-700 nm (red) $53 \%, 700-800 \mathrm{~nm}$ (far-red) 17\%, in the PAR-range 400-700 nm 83\%. Electrical power and PPF output of light treatments are shown in Table 1. PPF was measured at the height of plant top in November, December and January. The values are means of 25-40 measurements. Interlight PPF was measured at three heights both in interlight row and in row without interlight. The heights were 125, 175 (interlight) and $225 \mathrm{~cm}$ from the ground ( $\mathrm{n}=15)$ and the sensor was directed from leaf to light source (LI-COR quantum sensor LI-190 SA, LI-COR Inc., USA). Other technical details of the experiment are presented in Kaukoranta et al. (2015). 
Table 1. Electrical power used for supplemental lighting systems and PPF output ${ }^{-2}$ in greenhouse in winter at observation rows: LED-LED, HPS-LED and HPS-HPS

\begin{tabular}{ccccc}
\hline Treatment & \multicolumn{2}{c}{ Power $\left(\mathrm{W} \mathrm{m}^{-2}\right)$} & \multicolumn{2}{c}{ PPF $\left(\mu \mathrm{mol} \mathrm{s}^{-1} \mathrm{~m}^{-2}\right)$} \\
\hline & Top light & Interlight & Top light & Interlight \\
LED - LED & 128 & 64 & 160 & 125 \\
HPS - LED & 180 & 64 & 290 & 125 \\
HPS - HPS & 180 & 56 & 290 & 90 \\
\hline
\end{tabular}

The cucumber growing period was from November 19, 2013 to March 18, 2014. The plant density was 2.6 plants $\mathrm{m}^{-2}$ until the end of January and thereafter 2.2 plants $\mathrm{m}^{-2}$. Additional plants for measurements were located between the blocks.

The experiment was carried out with eight replicates in a randomized complete block, separate blocks at each greenhouse systems. Each replicate consisted of three plants. Selected model based on used experimental design:

$$
y_{i j k}=\mu+\operatorname{block}(G H)_{i j}+G_{i}+F_{k}+G^{*} \mathrm{FE}_{i \mathrm{ik}}+\varepsilon_{\mathrm{ijk}}
$$

where $y_{i j k}$ is response variable (mean of three plants), $\mu$ is the general mean, block $(G H)_{i j}$ is the random effect of $\mathrm{j}^{\text {th }}$ block at $\mathrm{i}^{\text {th }}$ greenhouse compartment, $\mathrm{GH}_{\mathrm{i}}$ is the fixed effect of greenhouse compartment, $\mathrm{FE}_{\mathrm{k}}$ is the fixed effect of $k^{\text {th }}$ lighting system, $\mathrm{GH}^{*} \mathrm{FE}_{\mathrm{ik}}$ is the interaction effect of greenhouse compartment and lighting system, and $\varepsilon_{\mathrm{ijk}}$ is residual error. Selected model is equivalent to the model for multilocation experiments (Singh et al. 1993, Littell et al. 2006, Manninen et al. 2008).

Model was fitted using REML-estimation method and SAS/MIXED procedure (SAS version 9.2.). Planned comparisons of t-type were used to compare treatment means (Mize and Schultz 1985). Comparisons were performed using HSD test in the SAS/MIXED.

The treatments were compared for light response of (1) photosynthesis, (2) light spectral irradiance distribution at adaxial and abaxial sides of leaves(3) leaf temperature, (4) leaf size and specific leaf weight (SLW), stem length and weight and vegetative dry matter accumulation, (5) water use efficiency (WUE), (6) yield accumulation and (7) yield formation efficiency.

(1) The photosynthesis measurements were made in the third week of January at the height of interlights with portable IRGA and connected cuvette CIRAS-2 (PP Systems Inc., USA). Chlorophyll content measurements at different heights: top, middle (interlights) and base were made with SPAD 502 (Spectrum Technologies Inc., USA) at the aisle both with and without interlight installation.

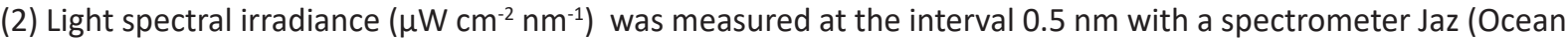
Optics Inc., USA) on January 20, 2014. The main light source during the measurements was artificial lighting. The light sensor was set horizontally at interlight height of $175 \mathrm{~cm}$ on adaxial and abaxial sides of leaves, and below $(-25 \mathrm{~cm})$ and above $(+25 \mathrm{~cm})$ the interlights on adaxial sides of leaves. Measurements from five points at each location were averaged.

(3) Leaf temperatures were measured in the second week of January with a FLIR PM 695 thermal camera (Flir Systems Inc., USA). Measurements from four points at each location were averaged.

(4) The leaf area (LI-3100 Area meter, LI-COR Inc., USA) and fresh and dry weights of leaves were determined once during the experiment from six plants and at the end of the experiment from eight plants per treatment, two plants per block in four blocks. SLW was calculated at the beginning of February and at the end of the experiment. Total number of leaves over the experiment, stem length and stem weight and dry matter content were determined at the end of the experiment.

(5) WUE was calculated from accumulated first-grade yield and crop transpiration. The transpiration was estimated from irrigation and drainage from the growing media measured at every block in the treatments. 
(6) Accumulation of yield as weight and number of fruits was recorded by harvesting fruits three times a week. The fruit dry matter content was determined three times during the experiment in December, February and March.

(7) Yield formation efficiency was determined for two plants per block in four blocks of a treatment, in total eight plants in a treatment. The efficiency was defined as a ratio of number of fruits to number of leaves on a plant at the end of the experiment. The number of fruits included harvested fruits and immature fruits at the end of the experiment.

\section{Results}

(1) The overall response of the net photosynthesis $\left(P_{n}\right)$ to light intensity was slightly stronger in the HPS-LED treatment than in the other treatments (Fig. 1) but the treatments did not significantly differ with regard to $P_{n \text { max }}, P_{n}$ at saturating light and the quantum yield. However, the light compensation point in LED-LED was at higher light level than in the other treatments $(p<0.01)$ (Fig. 1). The chlorophyll content did not differ between different leaf positions and treatments. The average amount was $38.7 \pm 1.9 \mu \mathrm{g} \mathrm{cm}^{-2}$.

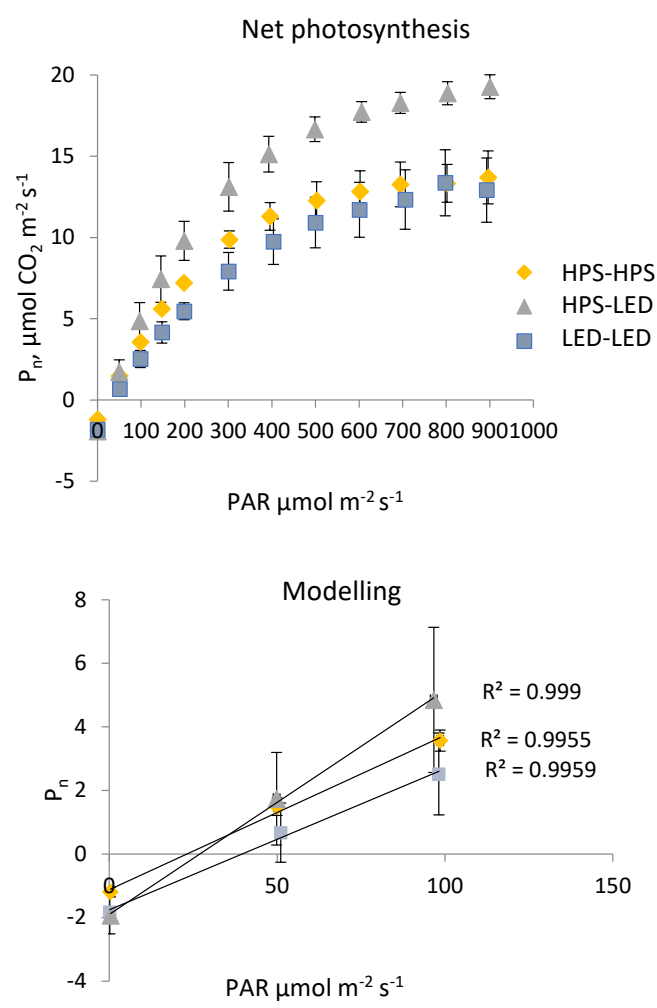

Fig. 1. Net photosynthesis $(\mathrm{Pn})$ measurements of cucumber leaves at the height of interlight in different light treatments and modelling thereafter

(2) The light spectral irradiance measurement showed that the HPS-LED treatment provided more diverse spectral distribution $(350-850 \mathrm{~nm})$ for the leaf layer at the interlight height $(175 \pm 25 \mathrm{~cm})$ than the LED-LED and HPS-HPS treatments. A small fraction of PAR-region $(400-700 \mathrm{~nm})$ irradiance penetrated through the leaves. In the HPS-LED and HPS-HPS treatments infrared irradiance from top HPS armatures reached leaves even at the interlight height and a significant proportion of the infrared radiation penetrated through the leaves (Fig. 2).

(3) Thermal camera images showed that leaf temperature, especially at the centre parts of leaf blades, were $4-5{ }^{\circ} \mathrm{C}$ higher under the HPS interlights than under the LED interlights (Table 2). On the top of the canopy, the leaf temperature under HPS top lights was $3-4{ }^{\circ} \mathrm{C}$ higher than that under the LED top lights (Table 2). HPS top lights also varmed the leaves at interlight height on the row without interlighting (Table 2). 

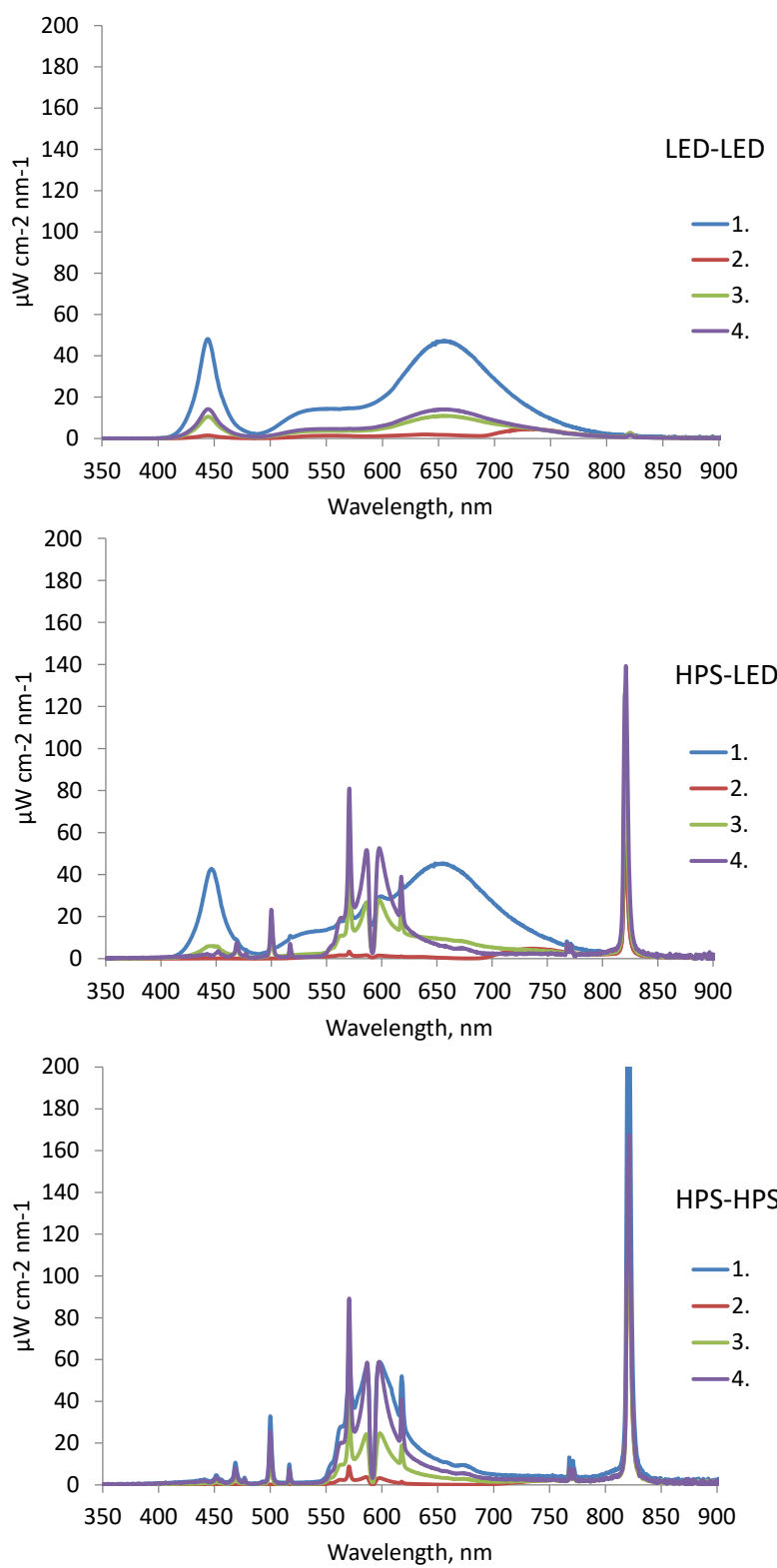

Fig. 2. Effects of different light treatments on the spectral irradiance distribution in the cucumber canopy. 1. on adaxial (upper) surface of a leaf at interlight height of $175 \mathrm{~cm}, 2$. on adaxial surface of a leaf at interlight height of $175 \mathrm{~cm}, 3$. on adaxial (upper) surface of a leaf below interlight $(175-25 \mathrm{~cm})$ and 4 . on adaxial (upper) surface of a leaf above interlight $(175+25 \mathrm{~cm})$

Table 2. Mean values of leaf temperature measurements under top lighting, beside interlighting and on the row without interlights. Leaf distance from interlights: HPS $30 \mathrm{~cm}$, LED $22 \mathrm{~cm}$

\begin{tabular}{cccc}
\hline Treatment & \multicolumn{3}{c}{ Temperature ${ }^{\circ} \mathrm{C}$} \\
\hline & Top light & Interlight & No interlight \\
LED-LED & 23.7 & 24.3 & 22.7 \\
HPS-LED & 25.7 & 26.5 & 25.5 \\
HPS-HPS & 25.7 & 28.1 & 26.2 \\
\hline
\end{tabular}

(4) At the end of the experiment, plants in the LED-LED treatment had longer stems and internodes, whereas the stem dry matter content and the number of leaves were lower than in the other treatments (Table 3 ). 
The leaf area of the LED-LED treatment at the end of the cultivation period was higher than in the other two treatments (Table 3). In LED-LED (data not shown), the leaf area of a whole plant was larger early in February, though not statistically significantly, and the difference from the other treatments continued to increase when solar radiation increased in February. The SLW at the end of the experiment was highest in the HPS-LED treatment, but the difference between LED-LED and HPS-HPS treatments was not significant (Table 4). The SLW at the beginning of February was lowest in LED-LED $\left(211 \pm 1.1 \mathrm{~g} \mathrm{~m}^{-2}\right)$ and slightly higher in HPS-LED $\left(221 \pm 3.1 \mathrm{~g} \mathrm{~m}^{-2}\right)$ than in HPS-HPS $\left(216 \pm 2.1 \mathrm{~g} \mathrm{~m}^{-2}\right)$ treatments.

5) The WUE was lower in LED-LED than in the other treatments (Table 3).

Table 3. Stem length, internode length, stem dry content, the number of leaves and water use efficiency of a whole plant. Different letters indicate statistical significance $p<0.05$.

\begin{tabular}{cccccc}
\hline Treatment & $\begin{array}{c}\text { Stem length } \\
\mathrm{m}\end{array}$ & $\begin{array}{c}\text { Internode length } \\
\mathrm{cm}\end{array}$ & $\begin{array}{c}\text { Stem } \\
\text { dry content \% }\end{array}$ & $\begin{array}{c}\text { Number of } \\
\text { leaves }\end{array}$ & $\begin{array}{c}\text { Water } \\
\text { I kg-1 grade } 1\end{array}$ \\
\hline LED-LED & $12.8 \mathrm{a}$ & $10.2 \mathrm{a}$ & $9.1 \mathrm{a}$ & $126 \mathrm{a}$ & $9.3 \mathrm{a}$ \\
HPS-LED & $12.0 \mathrm{~b}$ & $8.7 \mathrm{~b}$ & $9.8 \mathrm{~b}$ & $138 \mathrm{~b}$ & $7.6 \mathrm{~b}$ \\
HPS-HPS & $12.1 \mathrm{~b}$ & $8.8 \mathrm{~b}$ & $10.0 \mathrm{~b}$ & $137 \mathrm{~b}$ & $8.1 \mathrm{~b}$ \\
\hline
\end{tabular}

Table 4. Yield potential as fruit leaf ${ }^{-1}$ in $\%$ during whole growing period and specific leaf weight (SLW) and leaf area at the end of growing period, leaf $n=31$. Different letters indicate statistical difference $p<0.05$.

\begin{tabular}{cccc}
\hline Treatment & Fruit leaf $^{-1} \%$ & SLW g m$^{-2}$ & Leaf area cm $^{-2}$ \\
\hline LED-LED & $76 \mathrm{a}$ & $208 \mathrm{a}$ & $20363 \mathrm{a}$ \\
HPS-LED & $83 \mathrm{~b}$ & $222 \mathrm{~b}$ & $17361 \mathrm{~b}$ \\
HPS-HPS & $84 \mathrm{~b}$ & $210 \mathrm{a}$ & $17328 \mathrm{~b}$ \\
\hline
\end{tabular}

(6) The yield weight was highest under the HPS-LED treatment and lowest under LED-LED (Table 5). Number of fruits per plant was equal in HPS-LED and HPS-HPS treatments but lower in LED-LED. The fruit weight was highest in HPS-LED and fruit dry matter content tended to rise during the darkest winter months with LED interlighting in HPS-LED and LED-LED treatments (Table 6).

(7) The yield formation efficiency was lower in LED-LED than in the other treatments (Table 4).

Table 5. Yield in pieces and kilograms and average fruit weight at harvest in different treatments. Different letters indicate statistical difference $p<0.05$.

\begin{tabular}{cccccc}
\hline Treatment & $\begin{array}{c}\text { Grade } 1 \\
\text { kg plant }^{-1}\end{array}$ & $\begin{array}{c}\text { Total yield } \\
\text { kg plant }^{-1}\end{array}$ & $\begin{array}{c}\text { Grade } 1 \\
\text { pc plant }\end{array}$ & $\begin{array}{c}\text { Total yield } \\
\text { pc plant }^{-1}\end{array}$ & \multicolumn{2}{c}{ Fruit weight } \\
LED-LED & $18 \mathrm{a}$ & $21 \mathrm{a}$ & $59 \mathrm{a}$ & $76 \mathrm{a}$ & $306 \mathrm{a}$ \\
HPS-LED & $24 \mathrm{~b}$ & $28 \mathrm{~b}$ & $76 \mathrm{~b}$ & $90 \mathrm{~b}$ & $319 \mathrm{~b}$ \\
HPS-HPS & $21 \mathrm{c}$ & $26 \mathrm{c}$ & $70 \mathrm{~b}$ & $90 \mathrm{~b}$ & $297 \mathrm{c}$ \\
\hline
\end{tabular}

Table 6. Fruit dry matter content during experiment in different treatments. Different letters indicate statistical difference $p<0.05$.

\begin{tabular}{cccc}
\hline Treatment & December & February & March \\
\hline LED-LED & $2.97 \mathrm{a}$ & $3.00 \mathrm{a}$ & $3.15 \mathrm{a}$ \\
HPS-LED & $3.01 \mathrm{a}$ & $3.23 \mathrm{~b}$ & $3.22 \mathrm{a}$ \\
HPS-HPS & $2.86 \mathrm{a}$ & $2.92 \mathrm{a}$ & $3.12 \mathrm{a}$ \\
\hline
\end{tabular}

\section{Discussion}

In our experiment, where solar light was virtually absent in December and January (DLI 1.3-2.6 mol d-1), it was observed that net photosynthesis rate $\left(P_{n}\right)$ per unit area of leaf at equal light level (PPF) was higher in HPS-LED than in the other treatments, which may have been a result of a broader light spectrum from a mixture of lamp types, but also due to the higher leaf temperatures in the upper canopy. HPS interlight caused much higher leaf temperatures 
than LED interlight. However, the increased temperature did not affect negatively the chlorophyll content and the net photosynthesis. In soybean it has been observed that during the growth of leaves PPF levels do not affect the chlorophyll content, but it decreases under lower R:FR ratio (Torisky and Servaites 1984, Barreiro et al. 1992).

The light intensity at which net photosynthesis is zero (the light compensation point) is normally correlated positively with the value of light intensity required to saturate photosynthesis (Bazzaz and Carlson 1982). In this case the relationship was inversed; the higher light compensation point in LED-LED compared to the other treatments could indicate a specific adaptation to a low light level, as leaves were not capable of responding to increased light intensity during measurement (Trouwborst et al. 2011). The shade response is generally explained as a phytochrome-mediated reaction to a lowered red to far-red (R:FR) ratio, centred at 660 and $730 \mathrm{~nm}$, which results also in a shift in the chl a:b ratio (Barreiro et al. 1992). The R:FR ratios estimated from the red and far-red intensities of the LED and HPS lights in the experiment were approximately 2.5 to 3.5, which were high compared to sunlight (R:FR 1.2). Hogewoning et al. (2012) reported that the photosystem stoichiometry of cucumber leaves acclimated to the light spectrum environment where the leaves were grown, and combinations of different light spectra increased quantum yields.

Due to naturally low efficiency of photosynthesis, nearly all photons are utilized from both HPS and LED. However, there are differences in heat transfer modes. LED luminaires emit considerably less infrared radiation in general and even less in the direction of the light compared to HPS luminaires having the same nominal power. The bands of near infrared radiation, 810-840 nm emitted by HPS and 700-780 nm emitted by the LED top light, were well diffused and even transmitted through leaf layers.

After two months of growth in mid-winter with very little natural light, the LED-LED treatment plants were showing a lower temperature at canopy top and above interlights, and lower temperature difference between night and day compared to the other treatments. In the LED-LED treatment this resulted in low leaf appearance rate but faster stem elongation, faster expansion of leaves, lower flower initiation rate, and high fruit abortion rate. Hernandez and Kubota (2015) reached the same conclusion regarding leaf number reduction, but did not measure the leaf temperature. In a semi-closed greenhouse experiment during summer the appearance of the cucumber canopy was similar to that in the LED-LED treatment except the rate of abortion of fruit initials (Luomala et al. 2008); the yield in a semi-closed greenhouse with high $\mathrm{CO}_{2}$ was better than that in a conventional greenhouse.

Light quality affects leaf anatomical features. Leaves have been reported to become thicker with increasing blue light ratio and thinner with increasing red light despite increasing R:FR ratio (Schuerger et al. 1997, Hernandez and Kubota 2014). However, solar radiation often differs in comparison to experiments done solely under artificial light (Hernandez and Kubota 2014). Researchers showed that the cucumber transplant growth rate decreased under low solar DLI $5.2 \pm 1.2 \mathrm{~mol} \mathrm{~m}^{-2} \mathrm{~d}^{-1}$ when blue light was increased. In our results where solar radiation was included in total illumination, although the amount of supplemental blue light was higher in LED lighting than in HPS lighting, the leaves became thinner.

In experiments by Trouwborst (2010) with a combination of top HPS lighting and blue-red LED interlighting the total leaf area was lower and leaf mass higher than in HPS top lighting only, which was suggested to be due to less blue light in only HPS top lighting. Hernandez and Kubota (2014) claimed that blue light reduces leaf area and light interception per plant. In our experiment neither LED nor HPS as interlight affected the leaf area significantly with HPS top light. Because plants in the high-wire growing system are twice a week lowered based to the vertical growth rate of stems, the duration of exposing leaves to different light spectra and radiative heat may considerably affect the responses of plants to the spectrum of the supplemental lights that remain at fixed heights. The position of the interlight in relation to plant height may also have an impact on the plant response.

Despite longer internodes, the larger leaves resulted in a higher leaf area in LED-LED compared to the other treatments. Even though less radiative heat was transmitted to leaves in LED-LED, a resulting higher transpiration rate was seen. This in combination with the lower yield in LED-LED reduced the water use efficiency of LED-LED by more than one litre $\mathrm{kg}^{-1}$ fruit. The water cost is not significant, but energy used to remove the transpired vapour by opening and closing of screens, and increased ventilation needed in spring impact negatively the energy efficiency of an LED-LED lighting system.

The different light sources had an impact on total accumulated yield. The lowest yield was found in plants cultivated under LED-LED lighting partly due to the lowest total light intensity in this treatment. The higher light output efficiency $\left(\mathrm{mol} \mathrm{J}^{-1}\right.$ ) and higher electricity use efficiency could not compensate the negative effect of the lower 
total PAR light input in the LED-LED treatment in December and January, when there was virtually no solar light. During that period yield accumulation in LED-LED was significantly lower than in the other lighting treatments. When solar light increased in the latter half of February, the growth rate in LED-LED was equal to the other treatments.

In addition, the light interception in the canopy in the HPS top lighting treatment showed that the infrared light penetrated well into the lower leaf layers. This could have an important impact on fruit development through warming up the fruits and accelerating their maturity. Marcelis and Hofman-Eijer (1993) reported that development of cucumber fruits accelerated when temperature increased. The lower fruit temperature may have decreased fruit growth in LED-LED directly through reduced cell growth and indirectly through sink strength, but the fruit growth rate was equal to the other treatments with increasing solar radiation in the latter half of February. Marcelis (1996) presented that sink strength was depended on growing temperature and that high fruit dry weight is correlated to sink strength. In the LED interlighting treatment the fruit dry matter content was slightly higher than in the HPS interlighting treatment; this could have a positive impact on fruit keeping quality.

\section{Conclusion}

In conclusion, the highest yield was reached in HPS-LED lighting combination. The light use efficiency expressed in grams fruit fresh weight per mol-1 PAR was highest in the LED-LED lighting treatment but due to fewer fruits in mid-winter in the LED-LED treatment compared to the other treatments, the yield and yield potential were lowest in LED-LED. A combination of lower leaf temperature and lower light level resulted in increased leaf expansion and stem growth, lower flower initiation rate and higher fruit abortion rate in the LED-LED treatment. The lower total PAR level in the LED-LED treatment in combination with lower fruit temperature reduced the number of fruits. Whereas the higher leaf and fruit temperatures caused by higher heat radiation from HPS interlights compared to LED interlights did not improve fruit size. At the current stage of LED technology, the best lighting solution for high latitude winter growing appears to be HPS top lights combined with LED interlights. This provides the highest total PAR output, and sufficient radiative heat to the upper part of the canopy to maintain a high leaf and flower appearance rate, low fruit abortion rate, control leaf expansion, and provide enough radiative heat to fruits and lower leaves. However, a solution for the near future could be a combination of LED and HPS as top lights to be able to maintain a suitable temperature, but reduce energy use. This more flexible solution might actually also be used in a dynamic control allowing for gradually reducing leaf temperatures in the shift from day to night thus reducing the need for energy requiring humidity management.

\section{Acknowledgements}

We warmly thank Titta Kotilainen, PhD and Stiina Kotiranta, MSc from Valoya Ltd. for conducting the light spectral irradiance measurement from the cucumber canopy. We also thank technicians at our institute for their assistance during the experiment. Funding for this research was received from European Regional Development Fund.

\section{References}

Barreiro, R., Guiamet, J.J., Beltramo, J. \& Montaldi, E.R. 1992. Regulation of the photosynthetic capacity of primary bean leaves by the red: far-red ratio and photosynthetic photon flux density of incident light. Physiologia Plantarum 85: 97-101. https://doi.org/10.1111/j.1399-3054.1992.tb05269.x

Bazzaz, F.A. \& Carlsson, R. W. 1982. Photosynthetic acclimation to variability in the light environment of early and late successional plants. Oecologia 54: 313-316. https://doi.org/10.1007/BF00379999

Brazaityte, A., Duchovskis, P., Urbonaviciute, A., Samuoliene, G., Jankauskiene, J., Kasiuleviciute-Bonakere, A., Bliznikas, Z., Novickovas, A., Breive, K. \& Zukauskas, A. 2009. The effect of light-emitting diodes lighting on cucumber transplants and after-effect on yield. Zemdirbyste-Agriculture 96: 102-118.

Brown, C., Schuerger, A. C. \& Sager, J.C. 1995. Growth and Photomorphogenesis of Pepper Plants under Red Light-emitting Diodes with Supplemental Blue or Far-red Lighting. Journal of American Society for Horticultural Science 120: 808-813.

Hahn, E.J., Lee, Y.B. \& Ahn, C.H. 1996. A new method on mass-production of micropropagated chrysanthemum plants using microponic system in plant factory. Acta Horticulturae 440: 527-532. https://doi.org/10.17660/ActaHortic.1996.440.92

Hernandez, R. \& Kubota, C. 2014. Growth and morphological response of cucumber seedlings to supplemental red and blue photon flux ratios under varied solar daily light integrals. Scientia Horticulturae 173: 92-99. https://doi.org/10.1016/j.scienta.2014.04.035

Hernandez, R. \& Kubota, C. 2015. Physiological, Morphological, and Energy-use Efficiency Comparisons of LED and HPS Supplemental Lighting for Cucumber Transplant Production. HortScience 50: 351-357.

Hogewoning, S.W., Trouwborst, G., Maljaars, H., Poorter, H., van leperen W. \& Harbinson, J. 2010. Blue light dose-responses of leaf photosynthesis, morphology, and chemical composition of Cucumis sativus grown under different combinations of red and blue light. Journal of Experimental Botany 61: 3107-3117. https://doi.org/10.1093/jxb/erq132 
Hogewoning, S.W., Wientjes, E., Douwatra, P., Trouwborst, G., van leperen, W., Croce, R. \& Harbinson, J. 2012. Photosynthetic Quantum Yield Dynamics: From Photosystems to leaves. The Plant Cell 24: 1921-1935. https://doi.org/10.1105/tpc.112.097972

Hovi, T., Näkkilä, J. \& Tahvonen, R. 2004. Interlighting improves production of year-round cucumber. Scientia Horticulturae 102: 283-294. https://doi.org/10.1016/j.scienta.2004.04.003

Hovi-Pekkanen, T. \& Tahvonen, R. 2008. Effects of interlighting on yield and external fruit quality in year-round cultivated cucumber. Scientia Horticulturae 116: 152-161. https://doi.org/10.1016/j.scienta.2007.11.010

Jokinen, K., Särkkä, L. E. \& Näkkilä, J. 2012. Improving sweet pepper productivity by LED interlighting. Acta Horticulturae 956: 59-66. https://doi.org/10.17660/ActaHortic.2012.956.4

Kaukoranta, T., Särkkä, L.E. \& Jokinen, K. 2015. Energy efficiency of greenhouse cucumber production under LED and HPS lighting. Acta Horticulturae (in press: Greensys 2015).

Kong, S.-W., Chung, H.-Y., Chang, M.-Y. \& Fang, W. 2015. The Contribution of Different Spectral Sections to Increase Fresh Weight of Boston Lettuce. HortScience 50: 1006-1010.

Li, K., Yang, Q.-C., Tong, Y.-X. \& Cheng, R. 2014. Using Movable Light-emitting Diodes for Electricity Savings in a Plant Factory Growing Lettuce. HortTechnology 24: 546-553.

Littell, R.C., Milliken, G.A., Stroup, W.W., Wolfinger, R.D. \& Schabenberger, O. 2006. SAS for Mixed Models, Second Edition. Cary, NC: SAS Institute Inc. 814 p.

Luomala, E.-M., Särkkä, L. \& Kaukoranta, T. 2008. Altered plant structure and greater yield of cucumber grown at elevated CO2 in a semi-closed greenhouse. Acta Horticulturae 801: 1339-1345. https://doi.org/10.17660/ActaHortic.2008.801.164

Manninen, M., Sankari, S., Jauhiainen, L., Kivinen, T., Antila, P. \& Soveri, T. 2008. Effects of outdoor winter housing and feeding level on performance and blood metabolites of suckler cows fed whole-crop barley silage. Livestock Science 115:179-194. https://doi.org/10.1016/j.livsci.2007.07.014

Marcelis, L.F.M. 1996. Sink strength as a determinant of dry matter partitioning in the whole plant. Journal of Experimental Botany 47: 1281-1291. https://doi.org/10.1093/jxb/47.Special_Issue.1281

Marcelis, L.F.M. \& Hofman-Eijer, L.R.B. 1993. Effect of temperature on the growth of individual cucumber fruits. Physiologia Plantarum 87: 321-328. https://doi.org/10.1111/j.1399-3054.1993.tb01737.x

Mize, C.W. \& Schultz, R.C. 1985. Comparing treatment means correctly and appropriately. Canadian Journal of Forerstry Research 15: 1142-1148. https://doi.org/10.1139/x85-185

Murakami, K., Matsuda, R. \& Fujiwara, K. 2015. A difference in net photosynthetic rate between leaves grown with and without far-red light depends on the spectral distribution of measuring light. Abstract PS1.17 in ISHS Symposium Greensys 2015 Program and Abstract Book.

Ouzounis, T., Fretté X., Rosenqvist E. \& Ottosen, C.-O. 2014. Spectral effects of supplementary lighting on the secondary metabolites in roses, chrysanthemums, and campanulas. Journal of Plant Physiology 171:1491-99. https://doi.org/10.1016/j.jplph.2014.06.012

Ouzounis, T., Razi Parjikolaei B., Frette X., Rosenqvist E., Ottosen C.-O. 2015a. Predawn \& high intensity application of supplemental blue light decreases the quantum yield of PSII and enhances the amount of phenolic acids, flavonoids, and pigments in Lactuca sativa. Frontiers in Plant Science 6:19. https://doi.org/10.3389/fpls.2015.00019

Ouzounis, T., Rosenqvist, E. \& Ottosen, C.-O. 2015b. Spectral Effects of Artificial Light on Plant Physiolofy and secondaty metabolism: A Review. HortScience 50: 1128-1135.

Ouzounis T., Rosenqvist E. and Ottosen C.-O. 2015c. Spectral Effects of LEDs on Plant Physiology and Secondary Metabolism - a Review. HortScience 50: 1-8.

Schuerger, A.C., Brown, C.S. \& Stryjewski, E. 1997. Anatomical Features of Pepper Plants (Capsicum annuum L.) Grown under Red Light-emitting Diodes Supplemented with Blue or Far-Red Light. Annals of Botany 79: $273-282$. https://doi.org/10.1006/anbo.1996.0341

Singh, M., Ceccarelli, S. \& Hamblin, J. 1993. Estimation of heritability from varietal trails data. Theorical and Applied Genetics 86:437-441. https://doi.org/10.1007/BF00838558

Terashima, I., Fujita, T., Inoue, T., Chow, W.S. \& Oguchi, R. 2009. Green light Drives leaf Photosynthesis More efficiently than Red Light in Strong White light: Revisiting the Enigmatic Question of Why Leaves are Green. Plant Cell Physiology 50: $684-697$. https://doi.org/10.1093/pcp/pcp034

Torisky, R.S. \& Servaites, J.C. 1984. Effect if irradiance during growth of Glysine max on photosynthetic capacity and percent activation of ribulose 1,5-bisphosphate carboxylase. Photosynthesis Research 5: 251-261. https://doi.org/10.1007/BF00030026

Trouwborst, G., Hogewoning, S.W., Harbinson, J. \& van leperen, W. 2011. Photosynthetic acclimation in relation to nitrogen allocation in cucumber leaves in response to changes in irradiance. Physiologia Plantarum 142: 157-169. https://doi.org/10.1111/j.1399-3054.2011.01456.x

Trouwborst, G., Oosterkamp, J., Hogewoning, S.W., Harbinson, J. \& van leperen, W. 2010. The response of light interception, photosynthesis and fruit yield of cucumber to LED-lighting. Physiologia Plantarum 138: 289-300.

https://doi.org/10.1111/j.1399-3054.2009.01333.x 